\title{
LOS COLOQUIOS LATINOAMERICANOS DE FOTOGRAFÍA: HACIA UNA DEFINICIÓN DE LA FOTOGRAFÍA HECHA EN LATINOAMÉRICA
}

Latin American Colloquiums of Photography: Towards a definition of the photography made in Latin America

\author{
LETICIA RIGAT \\ UNIVERSIDAD NACIONAL DE ROSARIO/CONICET (ARGENTINA) \\ letirigat@hotmail.com https://orcid.org/0000-0002-4761-7142
}

RECIBIDO: 14 DE MARZO DE 2020

ACEPTADO: 04 DE SEPTIEMBRE DE 2020

RESUMEN: En el presente artículo nos proponemos reflexionar sobre los Coloquios Latinoamericanos de Fotografía que tuvieron lugar entre los años 1978 y 1996, en los que se buscó definir y categorizar a la fotografía latinoamericana. Dichos Coloquios se propusieron situar a la fotografía latinoamericana en el contexto de las actividades de la fotografía internacional, y propiciar una reflexión crítica sobre la identidad visual de las prácticas fotográficas de la región. En este sentido, buscamos indagar los documentos y actas de los coloquios a fin de proporcionar una lectura sobre el pensamiento sobre la fotografía latinoamericana en aquel contexto, partiendo del Primer Coloquio Latinoamericano de Fotografía realizado en México en 1978 y su evolución entre los encuentros posteriores: Segundo Coloquio Latinoamericano de Fotografía (México, 1981); Tercer Coloquio Latinoamericano de Fotografía (Cuba, 1984); Encuentro de Fotografía Latinoamericana (Venezuela, 1993); y Quinto coloquio Latinoamericano de Fotografía (México, 1996), intentando identificar los conceptos teóricos y visuales centrales.

PALABRAS CLAVE: Fotografía, Latinoamérica, Coloquios Latinoamericanos de Fotografía, Documentalismo, Arte Latinoamericano, Identidad.

ABSTRACT: In this article, we intend to reflect on the Latin American Colloquiums of Photography which took place between 1978 and 1996.During these colloquiums, Latin American photography tried to be defined and categorized. They aimed to place Latin American photography in the international photography activities context and to foster a critical thought about the visual identity of the photographic practices of the region. In this sense, we inquired into the documents and minutes from the above-mentioned colloquiums in order to give a reading about the thought of Latin American photography in that context, starting with the first Latin American Colloquium of Photography made in Mexico in 1978 and its evolution in the subsequent meetings: Second Latin American Colloquium of Photography (Mexico, 1981); Third Latin American Colloquium of Photography (Cuba, 1984); Latin American Photography Meeting (Venezuela, 1993); and Fifth Latin American Colloquium of Photography (Mexico, 1996) and trying to identify the central theoretical and visual concepts.

KEYWORDS: Photography, Latin America, Latin American Colloquiums of Photography, Documentary, Contemporary Art, Identity. 


\section{INTRODUCCIÓN}

En el presente artículo nos proponemos reflexionar sobre los Coloquios Latinoamericanos de Fotografía que tuvieron lugar entre los años 1978 y 1996, en los que se buscó definir y categorizar a la fotografía latinoamericana. En este sentido, buscamos indagar los documentos y actas de los coloquios a fin de proporcionar una lectura sobre el pensamiento sobre la fotografía latinoamericana en aquel contexto, partiendo del Primer Coloquio Latinoamericano de Fotografía realizado en México en 1978, y su evolución entre los encuentros posteriores (México, 1981; Cuba, 1984; Venezuela, 1993; y México, 1996), intentando identificar los presupuestos teóricos y visuales sobre los que se edificaron los relatos sobre la identidad visual de las prácticas fotográficas de la región entre las décadas del sesenta y noventa.

Este análisis se enmarca en un proyecto de investigación sobre Fotografía Latinoamericana Contemporánea y complementa un trabajo realizado recientemente sobre estas mismas fuentes documentales. En dicho trabajo, tomando como eje de análisis a las memorias de los Coloquios Latinoamericanos y sus respectivas muestras fotográficas, nos propusimos explorar los cambios en los modos de representación en la Fotografía Latinoamericana en los años 1990, período donde es posible observar una ruptura con el fotodocumentalismo de registro directo, estética que se había establecido como característica de la fotografía de la región en las décadas precedentes. Dicha ruptura se produce a partir de la creciente presencia de obras que incorporan operaciones artísticas como: la apropiación y alteración de archivos; la puesta en escena y el montaje; y la resignificación de prácticas fotográficas canónicas (Rigat, 2020). En el presente escrito buscamos centrarnos más específicamente en el estudio de los Coloquios Latinoamericanos y la definición de la Fotografía Latinoamericana.

Es posible considerar que los Coloquios Latinoamericanos de Fotografía contribuyeron a generar un paradigma en torno a la identidad visual de la Fotografía Latinoamericana desde aquel momento hasta ahora. En dichos encuentros se buscó definir a la fotografía latinoamericana más allá de una cuestión geográfica, identificando puntos en común en las producciones de los distintos países.

La categoría fotografía latinoamericana ha sido el eje de un amplio debate dentro de los estudios sobre fotografía. Una denominación que pese a los cuestionamientos sobre la existencia o no de prácticas fotográficas latinoamericanas vemos replicar en libros, exposiciones, coloquios, simposios, etcétera, y ser asociada con determinados temas, como la identidad, la memoria, el mestizaje o el colonialismo cultural; las particularidades de su paisaje; las desigualdades económicas; y los regímenes militares (Alonso, 2008).

Podemos señalar como un primer antecedente al uso de esta denominación a "La Primera Exposición de Fotografía Latinoamericana", organizada por la Unidad de Artes Visuales de la Organización de Estados Americanos (OEA), curada por el crítico de arte cubano José Gómez Sicre (Navarrete, 2017: 200). Se presentó en la Galería de la Unión Panamericana, en Washington 
D.C., entre el 12 de enero y el 15 de febrero de 1949 e incluyó a fotógrafos de Bolivia, Costa Rica, Guatemala, Paraguay, Perú y Venezuela¹. Sobre este acontecimiento, Navarrete afirma:

Hasta donde sabemos, una experiencia semejante no volvió a repetirse, y quedó sólo como un antecedente temprano -arbitrado en su reunión de imágenes, aunque alerta a los nuevos desarrollos del arte regional- de aproximaciones a la fotografía latinoamericana como una práctica de internacionalidad artística. (Navarrete, 2017: 200)

Una exposición que puede considerarse como el primer antecedente en la conformación de un imaginario en torno a la fotografía latinoamericana, pero en la que no se hicieron pronunciamientos específicos sobre qué caracteriza o define a las prácticas fotográficas de la región. Es en la década de 1970 cuando comienzan los estudios sistemáticos de las historias nacionales de la fotografía latinoamericana, en conjunción a la emergencia de un "movimiento fotográfico latinoamericano" (Navarrete, 2017: 201), que cobró visibilidad en 1978 con la realización en México del Primer Coloquio Latinoamericano de Fotografía. Este evento ha sido considerado por muchas investigaciones como un momento inaugural en la definición de la fotografía latinoamericana (González Flores, 2005; Martínez, 2008; Corp, 2015; Villares Ferrer, 2016; Navarrete, 2017; Carreras, 2018; Rigat, 2018), y un acontecimiento que impulsó la profesionalización e institucionalización de la fotografía en América Latina (Zerwes y Costa, 2017), dando lugar a la fundación de numerosos Consejos Nacionales de Fotografía, grupos de fotógrafos, revistas especializadas y espacios de enseñanza (Navarrete, 2000; Pérez Fernández, 2015).

Tomando al Primer Coloquio como un punto de inflexión en la Fotografía Latinoamericana, importantes investigaciones han abordado, además, el surgimiento de las primeras historias de la fotografía realizada en América Latina a partir de la década del ochenta. Dichas investigaciones realizan un abordaje sobre la construcción de los relatos e historias de la fotografía desde nuestro continente, echando luz sobre cómo en los mismos se han reproducido los ejes verticales de los centros a la periferia a partir de un modelo de la historia del arte norteamericano y europeo (Sampaio Barbosa, 2011; Zerwes, 2016; Navarrete, 2017).

El Primer Coloquio (1978) tuvo su continuación en sucesivos encuentros: Segundo Coloquio Latinoamericano de Fotografía (México, 1981); Tercer Coloquio Latinoamericano de Fotografía (La Habana, 1984); Encuentro de Fotografía Latinoamericana (Caracas, 1993) y el Quinto Coloquio Latinoamericano de Fotografía (México, 1996)2. Sobre los mismos Claudí Carreras explica que los primeros coloquios no se propusieron reivindicar y valorizar a determinados fotógrafos de forma individual, sino "situar en el mapa fotográfico internacional la

\footnotetext{
${ }^{1}$ Los participantes de la exposición fueron: Alfredo Linares (Bolivia); Esteban A. de Varona (Costa Rica); Julio Zadik (Guatemala); Luis Márquez, Agustín Mayo, Pedro Camps, Jesús M. Talavera, Raúl Conde, Lola Álvarez Bravo y Marianne (México); Federico Donna y A. Friedics (Paraguay); Martín Chambi, Rómulo M. Sassarego, González Salazar, Abraham Guillén y J. de Ridder (Perú); y Alfredo Boulton (Venezuela).

2 Asimismo estos cinco primeros encuentros pueden considerarse como los precursores de reuniones, coloquios y exhibiciones sobre Fotografía Latinoamericana que continúan hasta hoy: las Bienales de Fotografía organizadas por el Centro de la Imagen de México (desde 1980 a la actualidad); el Fórum de Fotografía Latinoamericana de Itaú Cultura (Brasil, 2007, 2010, 2013, 2016), las Jornadas de Fotografía que desde el 2005 a la actualidad se realizan en el Centro de Fotografía de Montevideo (Uruguay), Coloquio Latinoamericano de Fotografía de la Fundación Pedro Meyer, entre otros.
} 
producción fotográfica latinoamericana, generando premisas de producción que la diferenciaran del resto del mundo" (Carreras, 2018: 13).

Más allá de una distinción en términos geográficos, la categoría fotografía latinoamericana buscó definir una identidad visual en las prácticas fotográficas. En este sentido, las memorias que se produjeron en dichos encuentros son documentos importantes para analizar las producciones teóricas en torno al pensamiento sobre la fotografía de la región en el devenir de las décadas del setenta y noventa. A tal fin, en el presente trabajo nos proponemos una lectura de las actas de estos cinco coloquios buscando identificar las categorías que se han utilizado en la formación de la definición de la fotografía latinoamericana.

\section{LOS COLOQUios LATINOAMERICANOS DE FOTOGRAFÍA}

En 1978 tuvo lugar, en México, el Primer Coloquio Latinoamericano de Fotografía, organizado por el Consejo Mexicano de Fotografía y con los auspicios del Instituto Nacional de Bellas Artes y la Secretaría de Educación Pública. Conjuntamente se realizó la exhibición: Hecho en Latinoamérica, en el Museo de Arte Moderno de México D.F., entre el 11 de mayo y el 9 de julio. Ambos eventos contaron con una amplia participación de fotógrafos y ponentes de distintos países, con 3098 fotografías de 355 fotógrafos de Argentina, Brasil, Chile, Paraguay, Colombia, Cuba, Ecuador, Estados Unidos, Guatemala, México, Panamá, Perú, Puerto Rico, Uruguay y Venezuela. Desde la convocatoria los organizadores exponían los principales objetivos y principios del evento:

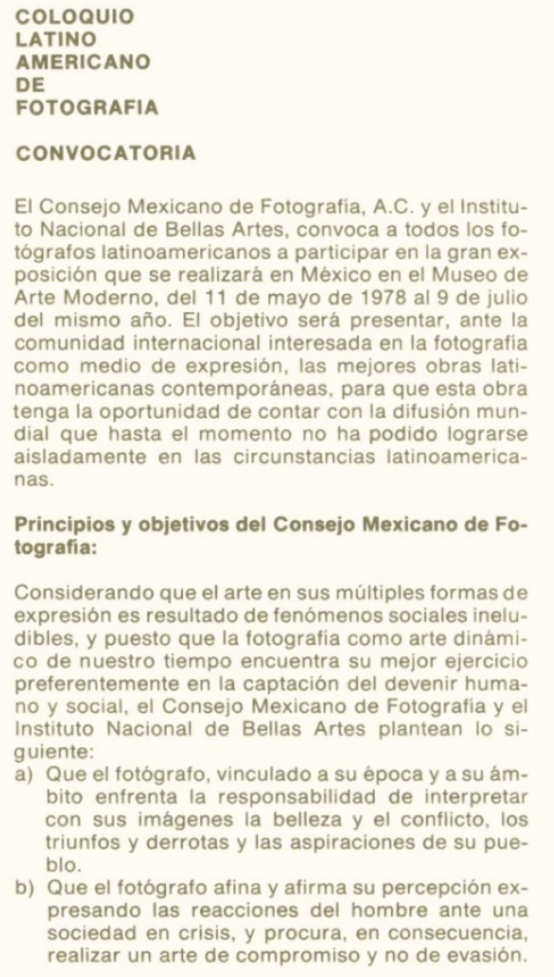

c) Que el fotógrafo debe afrontar, tarde o temprano. la necesidad de analizar la carga emotiva e ideobogica de la obra fotográfica propia y ajena, para comprender y definir los fines, intereses y propósitos que sirve.

Por todo ello, el Consejo Mexicano de Fotografia bajo los auspicios del INBA, convoca fraternalmente a los colegas de América Latina, acordes con estos principios, a hermanar mediante la imagen, las distintas identidades nacionales que permitan congregar la obra fotográfica más representativa de nuestro continente.

1. PATROCINIO:

El Consejo Mexicano de Fotografia, compuesto por destacados fotógrafos, teóricos y críticos en la materia, ha sumado sus esfuerzos técnicos y organizativos a los del Instituto Nacional de Bellas Artes y de su Museo de Arte Moderno de la Ciudad de México. para realizar simultáneamente el "Primer Coloquio Latinoamericano de Fotografia" y la "Primera Muestra Fotográfica de la Obra Contemporanea de Latide diversas instituciones oficiales y privadas.

2. CONDICIONES PARA LOS PARTICIPANTES: Pertenecer a la comunidad latinoamericana, chicana o puertorriqueña, cualquiera que sea el lugar de su residencia, y ejercer la fotografía como medio creativo de expresión.

3. ENVIO DE OBRAS:

Los. participantes deberán enviar, a su propio costo riesgo, un minimo de SEIS y un máximo de DIEZ otografias que formen un conjunto representativo de su obra.

as fechas limites para la recepción de obras son: Para los fotógrafos dentro del Territorio Mexicano: Diciembre 14, 1977.

Convocatoria. Primer Coloquio Latinoamericano de Fotografía (México, 1978). 
De la lectura de la convocatoria es posible reconocer dos ejes de discusión propuestos para el encuentro: 1) la búsqueda de posicionar internacionalmente a la fotografía latinoamericana, y 2) establecer los puntos principales de la labor de los fotógrafos latinoamericanos y los objetivos de las prácticas fotográficas en relación al contexto. El primero de estos puntos es destacado en su ponencia por la crítica de arte mexicana Raquel Tibol:

Aspiremos a que uno de los frutos de este coloquio sea la valoración de la fotografía latinoamericana dentro de la fotografía mundial, pues consideramos que existe una creación fotográfica genuinamente latinoamericana, dispersa en un mapa dentro del cual muchas veces se auspician y hasta fuerzan la desunión y el aislamiento, cuando la historia de nuestros pueblos nos empuja a la vinculación fraternal. Fruto de este vínculo podría ser un movimiento fotográfico latinoamericano eslabonado a través de puntos de identificación, a la vez que de respeto y, en casos necesarios o adecuados, de exaltación de las peculiaridades regionales o nacionales, con rechazo de toda estrechez excluyente. (Tibol, 1978: 43)

El segundo eje se va desarrollando y construyendo en las distintas ponencias a partir de ciertos interrogantes: ¿qué identifica o caracteriza a la fotografía latinoamericana? ¿Cuál es la labor del fotógrafo latinoamericano? Las respuestas a dichas preguntas reivindicaban al documentalismo de compromiso político y social, abogando por el realismo y condenando las intervenciones y manipulaciones de las imágenes. Esto último queda ilustrado por la presentación de Raquel Tibol, quien esgrimiendo a favor de la fotografía como medio de expresión autónomo frente a las artes plásticas, plantea que la fotografía sólo puede ser producida con lo objetivamente está frente a la cámara, por ello se impone como el medio por excelencia para registrar la vida en sus distintas manifestaciones: "de ahí su valor documental" (Tibol, 1978b: 19). Desde esta perspectiva, afirma que el fotógrafo latinoamericano debe contribuir a la representación de la realidad de la región, marcada por presiones políticas, económicas y militares (Tibol, 1978).

Tanto los organizadores como los participantes destacaban que la producción fotográfica profesional debía generar testimonios sobre la realidad y denunciar las injusticias sociales. En su ponencia, Pedro Meyer, presidente en aquel momento del Consejo Mexicano de Fotografía y una figura clave en la organización de casi todos los encuentros de esta época, afirmaba:

Con ello no quisiera dar la impresión de que la única fotografía que vale sea la llamada de denuncia social; pero si el fotógrafo escoge cualquier otra forma de manifestar su creatividad, de todas maneras tendrá que partir de la ineludible condición de la fotografía, es decir, de una realidad de la cual tomar sus imágenes y, a diferencia del pintor que puede inventar sus realidades, el fotógrafo tiene que entrar en contacto con su mundo y seleccionar de allí lo que desea. Si aquí es donde escogimos producir, de América Latina, de las entrañas de estas tierras tendrá que surgir las imágenes que habremos de realizar. (Meyer, 1978)

Conjuntamente al Coloquio se presentó la selección de imágenes en la exposición Hecho en Latinoamérica en el Museo de Arte Moderno de México DF. El comité de selección estuvo integrado por Jaime Ardila, Nacho López, Raquel Tibol, Pedro Meyer y Fernando Gamboa, quienes en el acta de selección manifestaban lo siguiente: 
Las obras recibidas representan variadas manifestaciones de las inquietudes fotográficas que prevalecen en nuestro continente, desde aquellas que muestran valores formales hasta las imágenes de naturaleza periodística, documentaria o humanista cuyos objetivos de explicación o confrontación las llevan a participar en la toma de conciencia respecto de los conflictos sociales, económicos y políticos de nuestros pueblos. (en AA.VV., 1978) ${ }^{3}$

Una concepción sobre la fotografía latinoamericana que puede reconocerse también en las notas que los fotógrafos enviaron para explicar su labor y los fundamentos de sus obras, notas que han sido incluidas junto a las fotografías que integraron la muestra, en la publicación de las memorias del Primer Coloquio Latinoamericano de Fotografía bajo el título Hecho en Latinoamérica (1978).

En las afirmaciones de los fotógrafos puede notarse una constante reivindicación de las cualidades de la fotografía para la representación fiel de lo real, de sus posibilidades técnicas de registro directo, que lleva a una reafirmación de la fotografía como documento de denuncia comprometido con un movimiento de cambio. Por ejemplo, Jorge Acevedo (1978: s/p) afirma en este sentido que el trabajo fotográfico debe buscar una expresión de la realidad y sus contradicciones: "Necesariamente esta producción artística deberá ponerse al servicio de la crítica y de la denuncia de la explotación, la marginación y la colonización [...]"4. Asimismo la fotógrafa mexicana Margarita Barroso Bermeo (1978: s/p) manifiesta que el fotógrafo debe estar comprometido y ser consecuente con su época para poder generar a través de la fotografía una protesta: "mi intención es mostrar una realidad que muchos pretenden ignorar, o que de alguna manera se nos trata de ocultar o deformar por considerarla hiriente, indignante, o molesta [...]".

Desde Chile, Patricio Guzmán Campos (1978: s/p) advierte que los latinoamericanos debemos compromiso y militancia en las luchas de nuestros pueblos, de esta manera:

debemos estar siempre atentos en la denuncia y ayudar mediante nuestra capacidad y sensibilidad, a luchar contra la injusticia social en que viven y trabajan las mayorías nacionales de nuestros pueblos indoamericanos.

Por su parte, Pedro Hiriart (1978: s/p) se detiene también en la idea del fotógrafo comprometido con su entorno social latinoamericano, sujeto a presiones exteriores, con imposiciones culturales y mecanismos de enajenación: "la obra es una búsqueda de identidad y un intento de subversión. Búsqueda de la identidad, borrada primero y negada sistemáticamente después. Subversión de la imagen para transformarla de un arma de control en un instrumento critico liberador". Julia Elvira Mejía (1978: s/p), destacando que su interés es captar lo cotidiano en su contexto social, afirma:

Este contexto social ha sido descrito en Latinoamérica por medio de situaciones de pobreza, desorden, y basura sin fin ni remedio, de invasiones masivas de valores ajenos, de explotaciones turísticas de culturas autóctonas, de represiones militares, de

\footnotetext{
3 Dicha muestra fue exhibida luego en diferentes espacios de Europa, cumpliendo el cometido inicial de internacionalizar la fotografía latinoamericana, y posiblemente también "contribuyó a la articulación de los estereotipos visuales que inciden en la región" (Carreras, 2018: 18).

4 Las citas que incluimos a continuación de los fotógrafos Jorge Acevedo, Margarita Barroso Bermeo, Patricio Guzmán Campos, Pedro Hiriart y Julia Elvira Mejía se encuentran en las Memorias del Primer Coloquio Latinoamericano de Fotografía Hecho en Latinoamérica, México, 1978, cuyas páginas no poseen numeración.
} 
manifestaciones de fervor religioso que conservan la esperanza y la opresión. (Mejía, 1978: s/p)

En consonancia con estas declaraciones, es posible reconocer en muchas de las notas de los fotógrafos una constante denuncia de la situación social latinoamericana en cuanto a choques de culturas, violencias, pobreza y marginación. En relación a los pueblos originarios y los afrodescendientes, hay una marcada crítica a su explotación como curiosidad turística y a su representación desde el exotismo. Son notables también las manifestaciones de los fotógrafos cubanos por la reivindicación de la revolución y sus líderes, y de la fotografía como instrumento de la historia, liberador y para crear conciencia social.

En 1981 se celebra nuevamente en México el Segundo Coloquio Latinoamericano de Fotografía, organizado por el Consejo Mexicano de Fotografía y el Instituto Nacional de Bellas Artes. En términos generales las bases de la convocatoria y de la selección de imágenes para la exposición Hecho en Latinoamérica, en el Palacio de Bellas Artes de México D.F., fueron las mismas que en el Primer Coloquio. El comité de selección estuvo integrado por Néstor García Canclini (Argentina); Max Kozloff (Estados Unidos); Héctor Méndez Caratini (Puerto Rico); Antonio Rodríguez (México); María Eugenia Haya (Cuba); Paul Leduc (México); y Pablo Ortiz Monasterio (México).

En esta ocasión, Pedro Meyer volvía a destacar a la fotografía documental como la expresión por excelencia de la fotografía en América Latina y a la identidad latinoamericana en relación a la colonización, las dependencias y sometimientos de nuestra región por el imperialismo. Convoca a reconocer las diferencias de los pueblos pero asimismo la unidad latinoamericana y el necesario compromiso con lo propio, reconociendo la represión y explotación sistemáticas que a lo largo de los siglos hemos padecido, a lo que agrega:

Hasta fechas recientes nos veíamos obligados, por falta de alternativas, a dirigir la mirada, en busca de orientación y hasta de apoyo, a los centros del poder cultural de las metrópolis, a los centros donde la fotografía estaba aparentemente más desarrollada. Finalmente, y a pesar de todo, ya no estamos mirando hacia las metrópolis para recibir su guía y favor. [...] Los estímulos nos están viniendo de nuestras propias tierras, de nuestros pueblos hermanos, de nuestras realidades culturales, políticas y sociales. (Meyer, 1981: 12)

Entre las intervenciones y ponencias que se presentaron podemos destacar: Néstor García Canclini (Argentina): "Fotografía e ideología: sus lugares comunes", comentada por Luis Pereira (Brasil), Salomón Cytrynowicz y Ktya Modoki (México); Lázaro Blanco (México): "La calidad vs el contenido en la imagen fotográfica”, comentada por Shifra Goldman (Estados Unidos); Raquel Tibol (México): "Mercado de arte fotográfico: liberación o enajenación”, comentada por Rafael Navarro (España) y Manfred Willman (Austria); Lourdes Grober (México): "Imágenes de miseria, folclor o denuncia”, comentada por Carlos Monsiváis (México) y Nik Hedges (Inglaterra); Mario García Joya (Cuba): "La posibilidad de acción de una fotografía comprometida dentro de las estructuras vigentes en América Latina", comentada por Mario Benedetti (Uruguay) y Rogelio Villareal (México); Roland Günter (Alemania): "La fotografía como instrumento de lucha", comentada por Martha Rosler (Estados Unidos) y Stefanía Bril (Brasil); Sara Facio (Argentina): "Investigación de la fotografía y colonialismo cultural en América Latina", comentada por Josune 
Dorronsoro (Venezuela) y Claudia Canales (México); Luis Carlos Bernal (Estados Unidos): "La fotografía como reflejo de las estructuras sociales", comentada por Víctor Muñoz (México) y Armando Cristeto (México); y Mex Kozloff (Estados Unidos): "La subjetividad, la fotografía y sus múltiples lecturas", comentada por Jorge de la Fuente (Cuba) y Giuliana Scime (Italia).

La sola lectura de los títulos permite deducir los ejes temáticos de los diálogos. Al igual que en el encuentro de 1978, la práctica documental es reivindicada, no obstante comienza a cuestionarse la supuesta objetividad fotográfica, manifestando la importancia del entorno sociopolítico y económico de la región, y que en las representaciones fotográficas hay un aspecto ideológico que interviene y no debe ser pasado por alto.

En este sentido, García Canclini, sirviéndose de la metáfora de la cámara oscura propone una lectura de la fotografía y la ideología, no como meros reflejos de lo real sino precisamente como reflejos invertidos de la vida real. Advierte así que la fotografía no copia la realidad y carece de objetividad, no se mueve en el terreno de la verdad sino en el de la verosimilitud. Concluye su exposición afirmando que las prácticas fotográficas comprometidas pueden contribuir a formar una nueva visión y a acabar con los estereotipos, "con las maneras reflejas de representar lo real que las ideologías dominantes nos imponen, y suscitar miradas nuevas, críticas, sobre esta tierra tan poco fotogénica" (Canclini, 1981: 18).

Por su parte, Roland Günter (1981) en "La fotografía como instrumento de lucha” advierte que la fotografía puede convertirse en un medio importante para representar la realidad de una manera más exacta y más compleja, por ejemplo hacer visible la conexión entre la explotación y la pobreza, la relación de estructuras sociales en la población con su modo de vida y su cultura popular, amenazada por el consumo y el colonialismo. Comentando el trabajo de Günter, Martha Rosler (1981) también reivindica a la fotografía como arma para la lucha social, pero advierte que no hay que olvidar los significados, discursos e ideologías que intervienen en los códigos de lo visible, puesto que la fotografía también puede reforzar y confirmar estereotipos perjudiciales 5 .

Sumado a lo anterior, en las ponencias se buscó definir y convocar a una fotografía comprometida. En este sentido, el fotógrafo cubano Mario García Joya (1981: 61) observa que la así llamada fotografía comprometida debe expresar los intereses de los pueblos y reivindicar los valores de la cultura latinoamericana. A lo que agrega que los fotógrafos latinoamericanos deben tener un núcleo de intereses comunes, con una acción coordinada a nivel continental a favor de la descolonización cultural, y la búsqueda de una identidad en la cultura nacional. A lo anterior, podemos sumar las declaraciones de Rogelio Villarreal (México) quien afirma que para crear una verdadera fotografía comprometida en Latinoamérica, los fotógrafos deben asumir un compromiso con sus pueblos, vinculándose con los movimientos populares y las clases trabajadoras (Villarreal, 1981: 66).

\footnotetext{
${ }^{5}$ En este sentido refuta a Günter afirmando que puede ser peligroso suponer que al representar a la gente en forma detallada y específica, se puede "superar la enajenación por medio de la distancia, de tal manera que la gente ya no es extraña, sino amistosa, de tal manera que se crea un sentimiento fraternal”, tomando como ejemplo a la exhibición "The Family of Man" que se organizó en Nueva York pero que circuló alrededor del mundo durante la Guerra Fría bajo el lema "un solo mundo", mientras su patrocinador -Estados Unidos— estaba tratando de forjar un nuevo orden mundial de dominación neoimeprialista (Rosler, 1981).
} 
Asimismo, en otras intervenciones se destacó que este compromiso no es únicamente el registro directo a través del dispositivo fotográfico, si en esto se pasa por alto que en las representaciones median ideas anteriores, y se reproduce una visión estetizante de lo que se busca fotografiar. Bajo esta premisa Lourdes Grobet (1981: 81) inicia su exposición afirmando que es necesario poder diferenciar cuándo las imágenes hechas de la miseria son denuncia y cuándo son folclóricas, señalando que es la actitud del fotógrafo la que marca la diferencia, su grado de compromiso y conciencia de la situación. Esta idea es reforzada por Carlos Monsiváis, quien advierte que la visión crítica debe superar la búsqueda de estetización de la imagen:

[...] a la fotografía le corresponde también el abandono y la crítica del exotismo y la pobreza romántica, el rechazo de toda pretensión de neutralizar al mundo, la negativa a asumir, con gozo estetizante, la parte por el todo. (Monsiváis, 1981: 87)

En síntesis, puede observarse que en este segundo encuentro latinoamericano de fotografía la fotografía latinoamericana continúa siendo definida en relación a la práctica documental y reivindicada como un medio de cambio, para generar conciencia social. No obstante, se refuerza la cuestión de lo ideológico, de las codificaciones culturales del sentido, donde el fotógrafo debe asumir una actitud crítica y comprometida con los propios actores sociales, con conciencia plena de las situaciones a fin de no reforzar, ni reproducir estereotipos; con el objetivo de encontrar una mirada latinoamericana que permita la liberación del colonialismo cultural.

En 1984 se llevó a cabo el Tercer Coloquio Latinoamericano de Fotografía, esta vez en la Casa de las Américas de Cuba, y la tercera exposición Hecho en Latinoamérica. Nuevamente la respuesta a la convocatoria fue contundente, se recibieron 3126 imágenes de 512 autores representando a 21 países. Los miembros del comité de selección fueron Raúl Corrales (Cuba), José Antonio Figueroa (Cuba), Fernell Franco (Colombia), Graciela Iturbide (México), Juca Martins (Brasil), Vladimir Sersa (Venezuela) y Jorge Timossi (Argentina).

Los interrogantes y debates rondaron en términos generales en lo mismo que en los encuentros anteriores". Entre las ponencias se encontraban: "La expresión de lo latinoamericano en la fotografía" de Raquel Tibol (México); "Premisas para la investigación de la fotografía latinoamericana" de María Eugenia Haya (Cuba); "¿Para quién y para qué se fotografía?" de Pedro Meyer (México); "Estética e imagen” de Néstor García Canclini (Argentina), "América Latina: una mitología de los medios de difusión masiva" de Esther Prada (Estados Unidos), entre otras. Asimismo el encuentro contó con la participación de Fidel Castro quien destacó a los Coloquios como constructores de la unión latinoamericana ${ }^{7}$. En los siguientes términos exponían los objetivos del Coloquio los organizadores:

Que el fotógrafo de estas tierras, que practica un arte característico de la modernidad, realice igualmente una tarea característica de nuestro específico mundo latinoamericano y caribeño, y en consecuencia se ponga a expresa, con el mayor rigor y la mayor aspiración universalizante de que sea capaz, la belleza de su entorno humano; un entorno donde ocupan un papel preponderante las luchas de nuestra América por encontrar su plena liberación en todos los órdenes; la incertidumbre de que esas luchas serán victoriosas. No

\footnotetext{
${ }^{6}$ En efecto, la convocatoria es una transcripción casi literal de la propuesta en el Primer Coloquio.

${ }^{7}$ La intervención de Fidel Castro aparece comentada de manera fragmentada en algunos documentos y libros, pero aún no se ha encontrado su transcripción completa (Carreras, 2018: 23).
} 
se trata, pues de optar entre una producción de marcado carácter esteticista u otra donde se haga patente la voluntad de denuncia y servicio, sino lograr una fotografía cuya encarnación más hermosa se haya plasmado por mostrar con lealtad el rostro de un continente mestizo dispuesto a conquistar para todos la justicia, hazaña creadora por excelencia. (en Carreras, 2018: 22) ${ }^{8}$

En este Tercer Coloquio se abandona el interrogante y se afirma la existencia de una fotografía latinoamericana cuyas prácticas tienen una historia, una estética y una función social propia. Distintos participantes señalaron la necesidad de una revisión historiográfica sobre la fotografía latinoamericana por fuera de las historias universales de la fotografía con su visión eurocéntrica. En este sentido, María Eugenia Haya reafirma la necesidad de una investigación de la historia de la fotografía desde una perspectiva propia:

En América Latina más que en ningún otro lugar se hace necesaria una revisión de todo lo establecido, que replanteemos de nuevo lo verdaderamente significativo desde el punto de vista de los intereses de nuestros pueblos y que nos preparemos para contar nuestra historia. (Haya, 2018 [1984]: 125-126) ${ }^{9}$

En las conclusiones finales del encuentro se planteó la importancia de continuar con los Coloquios, y se propuso como sede a Brasil, no obstante el cuarto coloquio no se realizó hasta 1993 en Caracas. Se propusieron, además, varias exposiciones internacionales que no se realizaron hasta que en 1992 se presentó "Image and Memory", organizada por Fotofest en Houston (Carreras, 2018).

Como es posible observar en los tres primeros coloquios, realizados entre los años 1978 y 1984, se propuso una definición de la fotografía latinoamericana en relación a sus posibilidades técnicas de representación fiel de lo real (registro directo). Una concepción de la fotografía que puede relacionarse a las teorías que en el mismo contexto intentaban definir la especificidad de la imagen fotográfica, poniendo en el centro la noción de dispositivo técnico y el concepto de lo fotográfico como objeto teórico. Se trató de un período marcado por el posestructuralismo, el posmodernismo y el régimen de visualidad que dejaba atrás el modelo del texto que había caracterizado los estudios sobre las imágenes en las décadas anteriores, buscando pensar lo que diferencia a la fotografía de otros medios de producción de imágenes, reivindicando con ello el carácter icónico-indicial de la fotografía (Peirce, 1987), el hecho de que la imagen resultante es

\footnotetext{
${ }^{8} \mathrm{La}$ memorias del Tercer Coloquio Latinoamericano de Fotografía fueron recientemente publicadas por primera vez en el año 2018 por el Centro de Fotografía de Montevideo (CDF) y con la labor de archivo de Claudí Carreras, a partir de lo cual pudo recuperar seis de las ocho presentaciones principales: Raquel Tibol (México), José Martins de Oliveira (Brasil), Pedro Meyer (México), María Eugenia Haya (Cuba), Esther Parada (Estados Unidos) y Néstor García Canclini (Argentina)

${ }^{9}$ En este punto cabe destacar la obra del historiador brasileño Boris Kossoy quien puede considerarse uno de los teóricos que más ha avanzado en la escritura de una historia latinoamericana de la fotografía desde una perspectiva propia: “[...] la historia de la fotografía en los países latinoamericanos no puede desvincularse del contexto social, político, económico, tecnológico y cultural en el que las imágenes tuvieron origen y evolución. Sin embargo, tampoco puede estudiarse sin comprender los procesos de la fotografía en Europa y Norteamérica, dado el carácter de esponja receptiva y sujeto en busca de reflejo con el que Latinoamérica se ha situado, frecuentemente, con respecto a esos sitios" (Kossoy 2001: 78).
} 
una huella de lo que representa (Krauss, 2002 [1985]; Barthes, 2005 [1989]; Schaeffer, 1990; Dubois, 2008 [1990] ${ }^{10}$.

A partir de esta concepción de la fotografía, se reivindicó al documentalismo de compromiso político como práctica por excelencia de la fotografía latinoamericana ${ }^{11}$ (Monroy Nars, 2000; Castellanos, 2000; Santos, 2014; Zerwes y Costa, 2017; Rigat, 2018). En dicha definición subyace además un pensamiento sobre Latinoamérica como unidad, como una comunidad sociocultural relacionada por experiencias históricas compartidas, en particular lo que refiere a la conquista; la experiencia colonial y sus continuidades; la constitución de lo nacional; las dependencias de los países centrales y el imperialismo; los regímenes autoritarios del siglo XX; los movimientos revolucionarios y de liberación.

Desde esta perspectiva, el auge que adquiere la categoría Fotografía Latinoamericana en los años setenta puede pensarse desde la dicotomía centro/periferia que ha marcado la relación del arte latinoamericano respecto al circuito del arte occidental, y su gusto por clasificar lo otro en términos geográficos y culturales (Mosquera, 2002). Este aspecto permite reflexionar sobre cómo en las ponencias y exhibiciones de los Coloquios antes mencionados, se propone una definición de lo latinoamericano a partir de aspectos diferenciadores que sirven como autoafirmación cultural, exaltando la localidad de producción, la representación del contexto y las particularidades histórico-sociales, revitalizando de esta manera el debate sobre las dependencias con los países centrales y la colonialidad ${ }^{12}$. Un proceso al que Nelly Richard explica en los siguientes términos:

Para los márgenes y las periferias culturales, es decir, para aquellas otredades que se habían visto expulsadas del dominio autocentrado de la modernidad occidental dominante, fue vital reivindicar la diversidad del contexto, para combatir el universalismo y el imperialismo del valor. Contexto quiere decir aquí localidad de producción, sitio enunciativo, coyuntura de debate, particularidad histórico-social de una trama de intereses y luchas culturales que especifican el valor situacional y posicional de cada realización discursiva. (Richard, 2007: 82)

\footnotetext{
${ }^{10}$ Cualidades que, sin referirse explícitamente a la teoría peirceana, ya habían sido destacadas entre otros, por: Walter Benjamin, André Bazin y Susan Sontag.

11 Esta reivindicación del fotodocumentalismo de compromiso político es observable previamente al Primer Coloquio Latinoamericano de Fotografía, con dos publicaciones que van en este sentido. La primera: América, un viaje a través de la injusticia (1970), que reúne una selección de imágenes de Latinoamérica realizadas por Enrique Bostelmman; y la segunda, Para verte mejor América Latina (1972) en la que se incluyen imágenes del fotógrafo venezolano Paolo Gasparini y textos del escritor cubano Edmundo Desnoes. Cabe señalar que paralelamente a estas reivindicaciones de la fotografía documental, ya en los años setenta comienzan a pronunciarse voces discordantes de fotógrafos, curadores y teóricos que defendían otras prácticas fotográficas. Dichas discusiones se hicieron presentes en los Coloquios Latinoamericanos de Fotografía, pero si tomamos los pronunciamientos de los organizadores es notable la preferencia en este período por el fotodocumentalismo como práctica por excelencia de la fotografía latinoamericana.

12 Tomo aquí en consideración algunas distinciones claves que señalan Restrepo y Rojas (2010): 1) la diferencia entre colonialismo como proceso y aparatos de dominio político y militares sobre las colonias, y colonialidad como fenómeno histórico más complejo que se extiende hasta nuestro presente y que refiere a un patrón de poder que opera a través de la naturalización de jerarquías territoriales, raciales, culturales y epistémicas, posibilitando la reproducción de las relaciones de dominación (noción que se remonta a la de colonialidad de poder de Quijano y Dussel), y 2) La distinción entre decolonización como superación del colonialismo (luchas anticoloniales, independencias políticas) de decolonialidad en tanto proceso que busca trascender la colonialidad.
} 
Entre los años sesenta y ochenta el contexto político internacional y latinoamericano -la Guerra Fría, los regímenes autoritarios que se sucedían en distintos países de la región, guerras en Centroamérica, la Revolución Cubana y la sandinista en Nicaragua, entre otros- revitalizó las manifestaciones artísticas que evidenciaran lo propio y criticaran las dependencias, dando lugar, como afirma Gerardo Mosquera, a categorías que sirvieron a los afanes de resistencia frente a la penetración cultural imperialista, planteando "ciertas generalizaciones de la siempre deslizante identidad cultural latinoamericana” (Mosquera, 2002: 130): el realismo mágico, lo real maravilloso, el mestizaje, el barroco, el afán constructivo, el discurso revolucionario, etcétera.

Casi diez años después del Tercer Coloquio, en 1993 se realizó en Caracas el Encuentro de Fotografía Latinoamericana, organizado y patrocinado por el Consejo Nacional de la Cultura de Venezuela y Fundarte. La muestra de fotografías estuvo curada por José Antonio Navarrete. Este encuentro buscaba dar continuidad a los Coloquios precedentes, de hecho fue considerado luego como el IV Coloquio Latinoamericano de Fotografía por los organizadores. No obstante, en este Encuentro es posible notar una ruptura con los paradigmas establecidos en los coloquios anteriores en torno a la producción fotográfica de la región, dando mayor lugar a las producciones más conceptuales, antes que al documentalismo, al valor testimonial y al posicionamiento ideológico.

En las ponencias hay un cambio de eje en las discusiones: "Fotografía ilimitada e inalcanzable" de Nelson Herrera Ysla (Cuba), comentada por Mariana Figarella (Venezuela) y Víctor Fuenmayor (Venezuela); "Balance de la investigación histórica de la fotografía latinoamericana, desde fines de la década del sesenta hasta la fecha" de Josune Dorronsoro (Venezuela), comentada por Robert Levine (Estados Unidos) y Fernando Castro (Perú); "Los desafíos de la tecnología a la creación fotográfica latinoamericana contemporánea" de Pedro Meyer (México), comentada por Pedro Vázquez (Brasil) y Antolín Sánchez (Venezuela); "Circulación de la fotografía latinoamericana en el sistema institucional de la cultura a escala internacional" de Pablo Ortiz Monasterio (México), comentada por Erika Billeter (Suiza) y André Rouille (Francia); "La otra fotografía... o la fotografía que nunca se cuenta" de Jorge Gutiérrez (Venezuela), comentada por Nelly Richard (Chile) y Charles Biastny- Rivera (Estados Unidos); "El testigo sospechoso: la fotografía y los medios de comunicación de masas" de Mel Rosenthal (Estados Unidos), comentada por Marcelo Brodsky (Argentina) y Miguel Río Branco (Brasil); y "La crisis de los '90 y primera plana" de Carlos Abreu (Venezuela).

Ya en la presentación, Ildemaro Torres planteaba la diferencia entre los tres primeros Coloquios y el Encuentro de 1993:

Se trata de recordar valiosas experiencias previas como las de los Coloquios de Fotografía celebrados en México y en la Habana, pero no necesariamente de retomarlas de donde ellas habían quedado, de valorar lo hecho como una guía para la planificación, pero con el cuidado de llevar adelante el nuevo compromiso a la luz de criterios de hoy. (Torres, 1984: 3)

En su intervención, Nelson Herrera Ysla proponía algunos interrogantes que ponían en duda la existencia de una fotografía latinoamericana: 
La fotografía Latinoamericana actual es también un enunciado ambiguo y un tanto resbaloso: ¿de cuál Latinoamérica estamos hablando? [...] ¿[de qué fotografía] la que interpreta o experimenta? ¿o la que sirve para difundir la mentira del subdesarrollo en bellísimas páginas de revistas o periódicos y vallas urbanas? (Ysla, 1993: 11)

Reforzando esta idea, Mariana Figarella, en su comentario a la ponencia de Herrera Ysla, plantea las limitaciones de las prácticas fotográficas desde los paradigmas establecidos en los coloquios anteriores y afirma que la fotografía latinoamericana debe dar un giro y dar paso a "propuestas más individualistas, intimistas y escépticas [...] Conceptos como puesta en escena, apropiación, reciclaje, descontextualización, deconstrucción ganan terreno dentro del nuevo lenguaje de la fotografía contemporánea latinoamericana” (Figarella, [1993] 2018: 24).

Estos cuestionamientos sobre las definiciones de la fotografía latinoamericana como un conjunto de prácticas nucleadas en la estética del documentalismo de compromiso político, continuaron en el Quinto Coloquio Latinoamericano de Fotografía. El mismo se realizó en México en 1996, organizado por El Centro de la Imagen de México y el Consejo Nacional para la Cultura y las Artes. En la presentación del evento, Patricia Mendoza —en ese entonces directora del Centro de la Imagen de México- propone retomar las inquietudes que se habían presentado en el Primer Coloquio (1978) y revisar cuáles habían sido los discursos que sustentaron el pensamiento sobre la fotografía realizada en América Latina. En base a esto, pone en duda los parámetros sobre los que se definió a la fotografía latinoamericana:

[...] preguntarnos si un concepto geográfico define la mirada o si genera una entidad; si las circunstancias históricas que nos unen o el lenguaje común marcan una importancia en la forma de ver, gestando un sueño casi bolivariano traducido a la mirada, o si lo que importa ahora es conciencia ética de su acción transformadora. (Mendoza, 2000 [1996]: 9)

El encuentro, además de una gran muestra fotográfica, contó con la realización de mesas centrales en las que se buscó profundizar la reflexión en torno a los usos de la imagen fotográfica, y la lectura de dos ponencias magistrales. La primera de ellas, titulada "Tres carabelas rumbos al próximo milenio", estuvo a cargo de Pedro Meyer. En la misma reconoce que desde aquel Primer Coloquio de Fotografía de 1978 se han suscitado profundos cambios, tanto en la fotografía como en América Latina. Haciendo referencia a la globalización, con sus grandes y aceleradas migraciones, como así también a los cambios que acarrea la digitalización, Meyer propone una serie de interrogantes con los que al igual que Mendoza pone en duda la existencia de una fotografía latinoamericana:

Si hablamos de fotografía latinoamericana, ¿a cuál fotografía nos estaremos refiriendo?, ¿a la que se origina en determinado territorio?, ¿a la que se crea a partir de cierta sensibilidad y herencia cultural?, ¿a la que solo retrata las caras de América Latina? Mi pregunta sería: ¿Qué condición debe reunir una obra para adquirir la carta de ciudadanía latinoamericana? (Meyer, 2000 [1996]: 17)

Genera con ello un desplazamiento de sus propias intervenciones en los coloquios anteriores en cuanto a la búsqueda de una definición homogénea y abarcadora de la fotografía latinoamericana, para pensar ahora no ya en términos geográficos y situados, sino en el nuevo contexto mundial de globalización, sobre lo cual afirma: 
[La fotografía latinoamericana] ha perdido esa nitidez conceptual con la que originalmente la habíamos trazado. Pienso que a medida que pasa el tiempo tendremos que ir encontrando nuevas fórmulas que presenten el tema de la identidad de manera más actual. Tendremos que ampliar el espacio que da cabida a lo que consideramos latinoamericano y al mismo tiempo responder a las necesidades particulares de identidad que se presentan distintas para cada individuo y para cada región. (Meyer, 2000 [1996]: 17)

En cuanto a los cambio en la fotografía, auspicia que las nuevas tecnologías pueden colaborar en ampliar el espacio de circulación de la fotografía latinoamericana; como así también se desplaza de la idea del documentalismo como medio de registrar fielmente lo real, para reivindicar otras prácticas fotográficas en las que se muestren las ficciones de los real y de las imágenes. Desde esta misma perspectiva, Joan Fontcuberta (España) en la segunda conferencia magistral, titulada "El elogio del vampiro", exponía sobre la necesidad de abandonar la idea de que la fotografía es un espejo, una representación fiel de lo real.

Las mesas temáticas se organizaron en torno a premisas como: "Medios Alternativos"; "La modernidad en la fotografía latinoamericana"; "Nuevas referencias históricas en Latinoamérica: Pasado"; "Nuevas referencias históricas en Latinoamérica: Presente"; "La experiencia de la transterritorialidad"; "Tendencias y alternativas de la fotografía documental"; entre otras. Si se observan en detalle los títulos de las mesas de debate, no sólo puede deducirse los temas abordados en general en el coloquio, sino también los cambios respecto a los encuentros anteriores. Los debates giraron en torno a nuevas cuestiones, que abrían el campo para pensar la fotografía realizada en América Latina desde nuevos ángulos, marcando una diferencia entre el pasado y el presente; donde el nuevo orden mundial y la globalización llevan a incorporar autores y visiones internacionales para volver a pensar los discursos que sirvieron para la reflexión de la fotografía latinoamericana hasta el momento. Se hace evidente asimismo la necesidad de pensar los cambios en las prácticas fotográficas con las nuevas tecnologías digitales y los nuevos medios de comunicación.

En contraste con los tres primeros Coloquios, es posible observar un cambio en la definición de la Fotografía Latinoamericana en los años noventa de la mano de críticos, teóricos y fotógrafos que planteaban que dicha categoría homogeneizaba bajo una misma rúbrica realidades dispares y diferenciales (Castellote, 2003), y resaltaban estereotipos: una América Latina rural y aislada, caracterizada por la violencia y la pobreza.

Un cambio de concepción que se vio reflejado también en las prácticas fotográficas que comenzaron a despejarse de lo que se había marcado como la plataforma común de los fotógrafos latinoamericanos, movidos por representar su contexto a través del documentalismo (Tibol, 1978b). Un síntoma de este cambio puede considerarse el número decreciente de trabajos de reportaje documental en las exposiciones de la época. Discontinuidades que podemos relacionar tanto al desarrollo de nuevos planteamientos curatoriales, como por un contexto internacional marcado por los cambios en las prácticas fotográficas a partir del cuestionamiento del estatus de documento de la fotografía.

En efecto, la ruptura con el fotodocumentalismo moderno puede ser considerada a la luz del debate más general que comenzó en los años noventa en torno a los impactos que las tecnologías digitales traerían en las prácticas fotográficas basadas en el soporte analógico. Un 
cambio en la naturaleza del dispositivo fotográfico que llevó a anunciar la muerte de la fotografía y la llegada a una nueva Era: la de la postfotografía; a partir de la cual la fotografía se liberaría del binomio documental-ficción (Green, 2007; Concha, 2011; Fontcuberta, 2016; Dubois, 2017; Rigat, 2019).

Sumado a esto, el documental mismo, como modalidad discursiva, fue revisionado en este contexto. El documental surge en la década de 1920 diferenciándose de las ficciones, las imágenes de arte y las actualidades, y en relación al conocimiento del funcionamiento del dispositivo técnico-indicial de producción de imágenes. El estilo principal del fotodocumentalismo en el siglo XX fue el registro directo, sin la intervención manifiesta del fotógrafo (más allá de cuestiones técnicas, de selección y recorte de la escena). En la última década del siglo XX, diferentes investigaciones han identificado una tendencia creciente en las prácticas documentales a poner en evidencia el nivel de la representación a partir de la intervención de los autores y un creciente desplazamiento de la tercera a la primera persona (Ledo, 1998; Bernini, 2008; Aguilar, 2015; Rigat, 2018b).

En este contexto la idea de una plataforma común de los fotógrafos latinoamericanos, movidos por representar su entorno, fue ampliamente cuestionada. Como hemos visto, ya en el Encuentro de Fotografía de Caracas (1993) comienzan a debatirse sobre la inclusión de prácticas fotográficas que incorporan operaciones artísticas como la puesta en escena, el uso de archivo, la intervención sobre las imágenes, etcétera; que rompen con la estética documental. Prácticas que, como anunciaba Meyer en el Quinto Coloquio, muestran las ficciones de lo real y de las imágenes.

Un hecho que ilustra este giro en el pensamiento sobre la fotografía latinoamericana puede considerarse el profundo rechazo que generó el enfoque de la curadora Erika Billeter en la exposición "Canto a la realidad. Fotografía latinoamericana 1860-1993" (1993), en el que afirmaba que la fotografía latinoamericana, al contrario de la europea y la norteamericana: "está totalmente orientada a la realidad de la existencia y desconectada por completo de cualquier veleidad que tiende a la experiencia estética" (Billeter, 1993: 30), negando con ello la capacidad de experimentación artística de la fotografía de la región.

\section{REFLEXIONES FINALES: FOTOGRAFÍA LATINOAMERICANA, UNA CATEGORÍA EN TENSIÓN}

Los Coloquios Latinoamericanos de Fotografía se convirtieron en el punto de encuentro de fotógrafos, curadores y críticos latinoamericanos, marcaron, por mucho tiempo, los paradigmas de la producción fotográfica de la región, pensando a Latinoamérica como un nexo de unión. Lograron, además, el objetivo de situar a la fotografía latinoamericana en el ámbito internacional promoviendo exposiciones colectivas en distintas partes del mundo (Carreras, 2018).

Pese a los debates sobre la existencia o no de una fotografía latinoamericana, la categoría fotografía latinoamericana logró instalarse como una denominación común para encuentros, coloquios, bienales, libros, exposiciones, etcétera, colaborando a generar un imaginario sobre la identidad visual en las prácticas fotográficas de la región.

Como hemos podido observar en el análisis precedente las definiciones sobre lo que caracteriza a la fotografía latinoamericana no han sido estables, ni unívocas. Tomando como referencia a los Coloquios Latinoamericanos de Fotografía, es posible afirmar que en los tres 
primeros, realizados entre los años 1978 y 1984, la fotografía latinoamericana se definía desde una localidad de producción, resaltando los complejos contextos sociales, culturales, económicos y políticos de Latinoamérica, y las similitudes de las experiencias históricas compartidas por los distintos países. Esta búsqueda de representar el contexto llevó a una reivindicación de las cualidades técnicas del dispositivo fotográfico para la representación fiel de lo real y del documentalismo de compromiso político y social como práctica por excelencia de la fotografía latinoamericana.

En la década del noventa se produce un cambio en estas conceptualizaciones de la mano de curadores, críticos de arte, fotógrafos e investigadores que planteaban que dicha caracterización era una noción reductora y homogeneizadora de la fotografía latinoamericana (Castellote, 2003; Corp, 2015), y que impulsaba una imagen de América Latina rural y aislada, caracterizada por la violencia y la pobreza. Un cambio de perspectiva que puede observarse también en las prácticas fotográficas que comenzaron a despegarse de lo que se había marcado como la plataforma común de los fotógrafos latinoamericanos movidos por representar su contexto a través del documentalismo. En esta década, como advierten Navarrete (2000) y Molina (2005) en la fotografía latinoamericana, se comienzan a problematizar los alcances del documental y es ahí que se generan las condiciones para "defraudar los estereotipos metropolitanos" proyectados sobre América Latina y a proporcionar una nueva lectura sobre las representaciones de lo latinoamericano.

Estos cambios se hacen visibles en los dos últimos Coloquios Latinoamericanos de Fotografía (1993 y 1996), tanto en las ponencias como en las muestras fotográficas. En las exposiciones de ambos encuentros ("Romper los Márgenes" y "Muestra de Fotografía Latinoamericana", respectivamente) puede observarse un número decreciente de reportajes de tipo documental respecto a los tres primeros Coloquios y la creciente presencia de obras fotográficas caracterizadas por la intervención de los fotógrafos, ya sea sobre el plano de la representación o sobre el plano de lo representado (Rigat, 2020). Un cambio que puede relacionarse tanto al desarrollo de nuevos planteamientos curatoriales como a: 1) la inclusión de la fotografía en el arte contemporáneo (Shiner, 2004; Corp, 2015; Rigat, 2018b), tras el debate posmodernos del arte, en el que la fotografía tuvo un lugar central en los cuestionamientos de los cánones del modernismo (Ribalta, 2004; Huyssen, 2006); 2) los cambios en el documentalismo como modalidad discursiva, con el desplazamiento de la tercera a la primera persona, a poner en evidencia el nivel de la representación a partir de la intervención de los autores (Ledo, 1998; Bernini, 2008; Aguilar, 2015); y 3) a un contexto internacional marcado por los debates en torno al status de documento de la imagen fotografía a partir de los cambios que traerían las tecnologías digitales; debate en el que se anunció la muerte de la fotografía y la llegada a una nueva Era: la de la postfotografía (Concha, 2011; Fontcuberta, 2016; Dubois, 2017; Rigat, 2019).

Desde los años 1990, curadores y críticos han expresado la necesidad de reconocer la heterogeneidad de las prácticas fotográficas latinoamericanas, identificando en la fotografía contemporánea de la región temáticas recurrentes, a las que resumen bajo las categorías de: historia, memoria e identidad. Entre ellos podemos ubicar al curador de la muestra "Mapas abiertos. Fotografía Latinoamericana 1991-2002”, Alejandro Castellote, en la que propone: 
[...] hacer un panorama de las propuestas surgidas a lo largo de la década de los noventa a partir de tres argumentos: "Rituales de identidad", "Escenarios" e "Historias alternativas", una especie de contenedores temáticos que permiten mostrar a algunos de los autores más reconocidos y a una nueva y extensa generación cuya obra se ha hecho visible en este período. (Castellote, 2003: 5)

De manera similar, el curador cubano Juan Antonio Molina, profundizando en la cuestión de la ruptura con el documentalismo en la fotografía latinoamericana en la última década del siglo $\mathrm{XX}$, señala:

Cualquier análisis suficientemente desprejuiciado de la fotografía contemporánea latinoamericana demostraría que mediante la fotografía no realista se están abriendo puertas alternativas para una relación entre los sujetos y la historia $[\ldots]$ estas relaciones alternativas con la historia se dan básicamente mediante la construcción de historias alternativas. (Molina, 2005: 29)

Es posible, entonces, afirmar que desde los años 1990 y bajo la denominación Fotografía Latinoamericana, se ha buscado redefinir los paradigmas que se habían establecido desde la década del setenta en relación a las prácticas visuales de la fotografía de la región. Un cambio que se ve reflejado tanto en los planteamientos curatoriales, las temáticas abordadas en las ponencias de los encuentros de la época, y en las prácticas fotográficas. Prácticas que se despegan del documentalismo e incorporan operaciones artísticas propias del arte contemporáneo. Operaciones artísticas que permiten representar historias alternativas (Molina, 2005) que se construyen mediante recursos visuales que resignifican los modos de representación, y los imaginarios latinoamericanos, recuperando el pasado en el presente (Giunta, 2014), principalmente en lo que respecta al pasado prehispánico, al colonialismo y al pasado reciente (en un contexto marcado por la recuperación de la democracia tras las vivencias de las dictaduras cívico militares, y la implementación de las políticas neoliberales). En relación a estos cambios Martínez afirma:

Los comentarios se producen de manera más sutil y buscan corroer las bases de las siempre pesadas plataformas de la oficialidad, proponiendo ironías, generando relaciones alegóricas con los símbolos maltrechos de patria, nación y obediencia. Se produce también la lucha contra las verdades impuestas - las mentiras vueltas verdades a fuerza de repetirlas mil veces- como una manera de desafiar los poderes que las generaron. (Martínez, 2008: 154)

Podemos decir que la categoría fotografía latinoamericana no se abandonó, como muchos pretendieron en los años noventa, sino que adquirió nuevas significaciones que engloban la heterogeneidad de las prácticas fotográficas, unidas conceptualmente por ciertas temáticas recurrentes, las cuales ya no son representadas desde el reportaje documental que ilustra el contexto, sino a partir de operaciones artísticas que problematizan, cuestionan y resignifican los imaginarios en torno a la identidad, la memoria y la historia latinoamericana, y podríamos decir también sobre la propia historia de la fotografía latinoamericana.

Nuevas prácticas fotográficas contemporáneas que trasgreden los límites de la fotografía documental, abriendo a nuevas formas de pensar las imágenes y la representación, no ya como meros espejos, sino como construcciones sociales que constituyen nuestros imaginarios y a la vez están atravesadas por dichos imaginarios. Una fotografía desde América Latina. Cambian con ello 
los modos de representación, pero no la voluntad de entendimiento y el compromiso con la realidad, nuestros contextos y sus múltiples tensiones. 


\section{BIBLIOGRAFÍA}

AA.VV. (1978). Memorias del Primer Coloquio Latinoamericano de Fotografía. México DF.: Consejo Mexicano de Fotografía.

AA.VV. (1981). Hecho en Latinoamérica. Segundo Coloquio Latinoamericano de Fotografía. México DF.: Consejo Mexicano de Fotografía.

AA.VV. (1993). Memorias. Encuentro de Fotografía Latinoamericana. Caracas: Fundarte.

AA.VV. (2000). V Coloquio Latinoamericano de Fotografía 1996. México DF.: Centro de la Imagen.

Aguilar, Gonzalo (2015). Más allá del pueblo: imágenes, indicios y políticas del cine. Buenos Aires: Fondo de Cultura Económica.

Alonso, Rodrigo (ed.) (2008). No sabe / no contesta. Prácticas fotográficas contemporáneas desde América Latina. Buenos Aires: Ediciones arte x arte.

BARTHES, Roland (2005 [1989]). La cámara lúcida. Buenos Aires: Paidós.

BerNinI, Emilio (2008) “Documentalismo contemporáneo”. Revista Kilómetro 111 7. Buenos Aires: Santiago Arcos editor.

BILLETER, Erika (1993). Canto a la realidad. Barcelona: Lunwerg.

Carreras, Claudí (2018). "Los Coloquios Latinoamericanos de Fotografía y la construcción de paradigmas en torno a la fotografía latinoamericana”. Carreras, Claudí (coord.). Tercer Coloquio Latinoamericano de Fotografía Tercer Coloquio Latinoamericano de Fotografía. Montevideo: CDF: 13-27.

Castellanos, Alejandro. "Pasajeros en tránsito. La fotografía en los años ochenta". Revista Tierra Adentro 105 (2000): 4-8.

CASTELLOTE, Alejandro (2003). Mapas abiertos: fotografía latinoamericana. Madrid: Lunwerg.

CONCHA, José P. (2011). La desmaterialización fotográfica. Santiago de Chile: Edición Metales Pesados.

CORP, Mathieu. "Las relaciones al pasado en la fotografía latinoamericana: por un acercamiento estético y antropológico de la fotografía”. Artelogie 7 (2015).

DubOIS, Philippe (2008 [1990]). El acto fotográfico y otros ensayos. Buenos Aires: La Marca.

DuBOIS, Philippe. "Da imagem-traço à imagem-ficção: o movimento das teorias da fotografia de 1980 aos nossos días". Discursos Fotográficos 13, 22 (2017): 32-51.

Figarella, Mariana (1993). "Comentarios". AA. VV. Memorias. Encuentro de Fotografía Latinoamericana. Caracas: Fundarte: 18-20.

FONTCUBERTA, Joan (2016). La furia de las imágenes. Notas sobre la postfotografía. Barcelona: Galaxia Gutenberg.

GARCía CANCLINI, Néstor (1981). "Fotografía e ideología: sus lugares comunes". AA.VV. Hecho en Latinoamérica 2. Segundo Coloquio Latinoamericano de Fotografía. México DF.: Consejo Mexicano de Fotografía: 17-20. 
GARCÍA GOYA, Mario (1981). "La posibilidad de acción de una fotografía comprometida dentro de las estructuras vigentes en América Latina". AA.VV. Hecho en Latinoamérica 2. Segundo Coloquio Latinoamericano de Fotografía. México DF.: Consejo Mexicano de Fotografía: 57-62.

GIUNTA, Andrea (2014). ¿Cuándo empieza el arte contemporáneo? Buenos Aires: Fundación Arte.

GONZÁLEZ FlORES, Laura (2005). "Fotografía mexicana contemporánea. Un modelo para armar”. Benítez, Issa (ed.). Hacia otra historia del arte en México. México: Curare: 79-108.

GrEen, David (ed.) (2007). ¿Qué ha sido de la fotografía? Barcelona: Gustavo Gili.

Grobet, Lourdes (1981). "Imágenes de miseria: folclor o denuncia". AA.VV. Hecho en Latinoamérica 2. Segundo Coloquio Latinoamericano de Fotografía. México DF.: Consejo Mexicano de Fotografía: 81-84.

GÜNTER, Roland (1981). "La fotografía como instrumento de lucha". AA.VV. Hecho en Latinoamérica 2. Segundo Coloquio Latinoamericano de Fotografía. México DF.: Consejo Mexicano de Fotografía: 43-47.

HAYA, María Eugenia (2018 [1984]). "Premisas para la investigación de la fotografía latinoamericana". Carreras, Claudí (coord.). Tercer Coloquio Latinoamericano de Fotografía. Montevideo: CDF: 123-138.

Herrera YSLA, Nelson (1993). "Fotografía ilimitada e inalcanzable". AA. VV. Memorias. Encuentro de Fotografía Latinoamericana. Caracas: Fundarte: 11-17.

Huyssen, Andreas (2006). Después de la gran división. Buenos Aires: Adriana Hidalgo.

Kossoy, Boris (2001). Fotografía e historia. Buenos Aires: La Marca.

KRAUSS, Rosalind (2002). Lo fotográfico por una teoría de los desplazamientos. Barcelona: Gustavo Gili.

LEDO, Margarita (1998). Documentalismo Fotográfico. Éxodo e identidad. Madrid: Cátedra.

MARTínez, Liliana (2008). "Aproximación a la fotografía en Latinoamérica". Alonso, Rodrigo (ed.). No sabe / no contesta. Prácticas fotográficas contemporáneas desde América Latina. Buenos Aires: Ediciones arte x arte: 143-158.

MENDOZA, Patricia (2000 [1996]). "Presentación". AA.VV. V Coloquio Latinoamericano de Fotografía. México: Centro de la Imagen: 90-100.

MeYer, Pedro (1978) "Presentación”. AA.VV. Memorias del Primer Coloquio Latinoamericano de Fotografía. México DF.: Consejo Mexicano de Fotografía: 17-20.

MeYer, Pedro (1981). "Palabras de presentación". AA.VV. Hecho en Latinoamérica 2. Segundo Coloquio Latinoamericano de Fotografía. México DF.: Consejo Mexicano de Fotografía: 9-12.

MEYer, Pedro (2000 [1996]). "Tres carabelas rumbo al nuevo milenio". AA.VV. V Coloquio Latinoamericano de Fotografía. México: Centro de la Imagen: 15-20.

MolinA, Juan Antonio (2005). "La historia a contrapelo. Modelos visuales y teóricos para el análisis de la fotografía contemporánea en América Latina”. Situaciones artísticas Latinoamericanas. San José de Costa Rica: TEOR/éTICA/The Getty Foundation. 
MONROY NARS, Rebeca. "Gamas, facetas y recuadros del fotodocumentalismo en México". Tierra adentro 105 (2000): 19-24.

MonsiváIs, Carlos (1981). "Comentarios". AA.VV. Hecho en Latinoamérica 2. Segundo Coloquio Latinoamericano de Fotografía. México DF: Consejo Mexicano de Fotografía: 85-87.

Mosquera, Gerardo (2002). Caminar con el diablo. Textos sobre arte, internacionalismo y culturas. Madrid: Exit publicaciones.

NAVArRete, José Antonio. (2000) “A intervalos a la distancia. Fotografía Mexicana". Tierra Adentro 105 (2000): 49-53.

Navarrete, José Antonio (2017). Fotografiando en América Latina. Ensayos de crítica bistórica. Montevideo: CDF.

PeIRCE, Charles S. (1987 [1897]). La ciencia semiótica. Buenos Aires: Nueva Visión.

PÉrEZ FERnÁNDEZ, Silvia. "Liberación o (in) dependencia: tensiones entre identidad latinoamericana y ruptura con la tradición en la fotografía argentina (1978-1984)”. Afuera X, 15 (2015).

RESTREPO, Eduardo y ROJAS, Axel (2010). Inflexión decolonial: fuentes, conceptos y cuestionamientos. Popayán: Editorial Universidad del Cauca.

RiBALtA, Jorge (ed.) (2004). Efecto Real. Debates posmodernos sobre fotografía. Barcelona: Gustavo Gili.

RICHARD, Nelly (2007). Fracturas de la memoria. Arte y pensamiento crítico. Buenos Aires: Siglo XXI.

RigAT, Leticia. "Fotografía Latinoamericana Contemporánea: crítica poscolonial y renovación de los lenguajes. El caso Brasil”. Crítica Cultural 13 (2018): 233-244.

RigAT, Leticia. "Fotografía contemporánea: la reconfiguración de los modos de representación en el documentalismo". DeSignis 28 (2018b): 59-73.

RigAT, Leticia. "De lo fotográfico a la fotografía digital contemporánea: la imagen en el intercambio discursivo". Fotocinema. Revista científica de cine y fotografía 18 (2019): 193-213.

Rigat, Leticia. "Los Coloquios Latinoamericanos de Fotografía y la reconfiguración de las prácticas fotográficas". Dixit 32 (2020): 33-45.

Roler, Martha (1981). "Comentario". AA.VV. Hecho en Latinoamérica 2. Segundo Coloquio Latinoamericano de Fotografía. México DF.: Consejo Mexicano de Fotografía: 48-53.

SAMPAIO BARBOSA, Carlos. "Balance historiográfico de la fotografía latinoamericana a partir de una perspectiva brasileña. Metodologías y ejes de análisis". Artelogie 7 (2011).

SANTOS, Ana. "Sobre essa tal de fotografía latinoamericana: uma análise do processo de demarcação de uma suposta essência fotográfica latina”. Contracampo 29, 1 (2014): 153-168.

SCHAEFFER, Jean Marie (1990). La imagen precaria. Del dispositivo fotográfico. Cátedra: Madrid.

SHINER, Larry (2004). La invención del arte. Una historia cultural. Barcelona: Paidós. 
TiBOL, Raquel (1978) "Bases para una metodología crítica de la fotografía en América Latina”. AA. VV. Memorias del Primer Coloquio Latinoamericano de Fotografía. México DF.: Consejo Mexicano de Fotografía: 43-46.

TiBOL, Raquel (1978b). "Presentación". AA.VV. Hecho en Latinoamérica. Primer Coloquio Latinoamericano de Fotografía. México DF.: Consejo Mexicano de Fotografía: 17-20.

TORRES, Ildemaro (1993). "Presentación". AA. VV. Memorias. Encuentro de Fotografía Latinoamericana. Caracas: Fundarte: 3.

Villareal, Rogelio (1981). "Comentario". AA.VV. Hecho en Latinoamérica 2. Segundo Coloquio Latinoamericano de Fotografía. México DF: Consejo Mexicano de Fotografía: 63-66.

VILLARES FERrer, Mónica. "Hecho en Latinoamérica: la invención de la Fotografía Latinoamericana”. Sures 7 (2016).

ZERWES, Erika. "A fotografia humanista e a construção de uma historiografia sobre a fotografia latino-americana”. Passo Fundo: História: Debates e Tendências 16, 2 (2016): 314-327.

ZERWeS, Erika y COSTA, Eduardo. "Os Colóquios Latino-Americanos de Fotografia e a institucionalização de uma fotografia brasileira”. Revista de Estudios Brasileños 4, 8 (2017): 145-159. 